\title{
O CRIME DE CORRUPÇÃO NO SETOR PRIVADO: ESTUDO DE DIREITO COMPARADO E A NECESSIDADE DE TIPIFICAÇÃO DO DELITO NO ORDENAMENTO JURÍDICO BRASILEIRO
}

\author{
Dissertação de Mestrado \\ Orientador: Professor Titular Dr. Miguel Reale Júnior
}

UNIVERSIDADE DE SÃO PAULO

FACULDADE DE DIREITO

São Paulo-SP

2015 


\title{
CONRADO ALMEIDA CORRÊA GONTIJO
}

\section{O CRIME DE CORRUPÇÃO NO SETOR PRIVADO: ESTUDO DE DIREITO COMPARADO E A NECESSIDADE DE TIPIFICAÇÃO DO DELITO NO ORDENAMENTO JURÍDICO BRASILEIRO}

\begin{abstract}
Dissertação apresentada à Banca Examinadora do Programa de Pós-Graduação em Direito, da Faculdade de Direito da Universidade de São Paulo, como exigência parcial para obtenção do título de Mestre em Direito, na área de concentração Direito Penal, Medicina Forense e Criminologia, sob a orientação do Professor Titular Dr. Miguel Reale Júnior.
\end{abstract}

UNIVERSIDADE DE SÃO PAULO

FACULDADE DE DIREITO

São Paulo-SP

2015 
Autorizo a reprodução e divulgação parcial deste trabalho, por qualquer meio convencional ou eletrônico, para fins de estudo e pesquisa, desde que citada a fonte.

\section{Serviço de Biblioteca e Documentação \\ Faculdade de Direito da Universidade de São Paulo}
Gontijo, Conrado Almeida Corrêa
G 649c O crime de corrupção no setor privado: estudo de
direito comparado e a necessidade de tipificação do
delito no ordenamento jurídico brasileiro / Conrado

Almeida Corrêa Gontijo. -- São Paulo: USP / Faculdade de Direito, 2014.

$250 \mathrm{f}$.

Orientador: Prof. Titular Dr. Miguel Reale Júnior

Dissertação (Mestrado), Universidade de São Paulo, USP, Programa de Pós-Graduação em Direito, Direito Penal, Medicina Forense e Criminologia, 2014.

1. Corrupção. 2. Setor privado. 3. Direito comparado I. Reale Júnior, Miguel. II. Título. 
GONTIJO, Conrado Almeida Corrêa. O crime de corrupção no setor privado: estudo de direito comparado e a necessidade de tipificação do delito no ordenamento jurídico brasileiro. 2015. 250 f. Dissertação (Mestrado). Faculdade de Direito da Universidade de São Paulo, São Paulo, 2015.

\section{RESUMO}

A presente dissertação de mestrado versa sobre o fenômeno da corrupção no setor privado e sobre a necessidade de sua tipificação no ordenamento jurídico do Brasil, país em que a celebração de pactos sceleris é recorrente, seja na esfera pública, seja no âmbito das relações entre particulares. Inicia-se o trabalho acadêmico com a análise das características elementares do fenômeno da corrupção, que em sua conformação tradicional apenas é sancionado pelo Direito Penal nas hipóteses em que agente vinculado ao setor público integre o acordo delitivo. Nos últimos anos, todavia, nota-se que também atos de corrupção perpetrados na esfera privada têm recebido disciplina jurídico-penal, circunstância justificada pela hodierna conjuntura socioeconômica. Em seguida, é abordado o tratamento dispensado à corrupção privada pelos organismos supranacionais e internacionais de criação de Direito, com enfoque para o Conselho da União Europeia, o Conselho da Europa, a Organização das Nações Unidas (ONU) e a Organização dos Estados Africanos, que já criaram diplomas normativos voltados ao tratamento do fenômeno. Analisam-se, posteriormente, sob um viés comparado, os ordenamentos jurídicos da Inglaterra, da Alemanha, da França, da Itália e da Espanha, que dispõem de preceitos legais incriminadores para coibir os acordos corruptivos firmados entre particulares. A seguir, considerada a heterogeneidade das soluções tocantes ao assunto oferecidas pelas entidades mencionadas e pelo Direito alienígena, desenvolve-se sugestão de modelo político-criminal a ser acolhido pelo legislador brasileiro, com a identificação de bem jurídico que deve ser contemplado no momento de definição dos comportamentos caracterizadores da corrupção no setor privado. Por fim, direcionando cuidados à observância dos princípios fundamentais da ultima ratio, da subsidiariedade, da fragmentariedade e da legalidade estrita, faz-se proposta de tipificação penal do fenômeno, com a definição das condutas de corrupção privada que julgamos devam ser sancionadas na ordem jurídica brasileira.

Palavras-chave: corrupção, corrupção no setor privado 
GONTIJO, Conrado Almeida Corrêa. The corruption offense in the private sector: a comparative law study and the need for its classification in the brazilian legal system. 2015. 250 p. Degree (Master) - Faculty of Law, University of São Paulo, São Paulo, 2015.

\begin{abstract}
The present master's degree dissertation speaks of the phenomenon of corruption in the private sector and of the need for its classification within the Brazilian legal system, a country where pactos sceleris agreements happen quite often, whether in the public sector or in relations between individuals. The academic work begins with the analysis of the elemental features of the corruption phenomenon, which, in its traditional conformation, is only sanctioned by criminal law in cases where the agent linked to the public sector integrates the offense agreement. In recent years, however, it is noticed that acts of corruption committed in the private sphere have also received legal and penal discipline, a circumstance justified by contemporary socioeconomic factors. After that, it addresses the treatment meted out to private corruption by supranational and international bodies of Law creation, focusing on the European Union Council, the Europe Council, the United Nations (UN) and the Organization of African States, which have already created regulatory instruments aimed at addressing such phenomenon. It then analyses, under a compared bias, the legal systems of England, Germany, France, Italy and Spain, which have incriminating legal provisions to restrain corruptive agreements between private individuals. Then, considering the heterogeneity of solutions regarding the subject offered by the aforementioned entities and by the Alien law, a suggestion of politicalcriminal model to be accepted by the Brazilian legislature is developed, with the identification of legal content that must be considered when setting behaviours featured as corruption in the private sector. Finally, carefully complying with the fundamental principles of ultima ratio, as well as subsidiarity, fragmentary and strict legality, a penal classification of the phenomenon is proposed, with the definition of private corruption conducts we believe should be sanctioned in the Brazilian Law.
\end{abstract}

Keywords: sentence - judgment - interpretation - interpretation of judicial decisions. 


\section{SUMÁRIO}

\section{CORRUPÇÃO: CONCEITOS E EVOLUÇÃ̃O}

1.1. A acepção do termo corrupção e questões introdutórias

1.2. A clássica faceta da corrupção: fenômeno relacionado a atos de abuso de poder de funcionários públicos e agentes a eles equiparados

1.3. A corrupção como fenômeno relacionado a atos de abuso de poder no setor privado

1.4. As críticas à tipificação do crime de corrupção no setor privado

\section{A CORRUPÇÃo NO SETOR PRIVADO E O SEU TRATAMENTO NOS} ÂMBITOS INTERNACIONAL E SUPRANACIONAL .

2.1. As iniciativas internacionais e supranacionais de combate à corrupção no setor privado

2.2. Documentos jurídicos europeus de combate à corrupção no setor privado .........................54

2.2.1. A Ação Comum 98/742/JAI da União Europeia ............................................................54

2.2.2. A Convenção Penal sobre a corrupção do Conselho da Europa...................................60

2.2.3. A Decisão Marco 2003/568/JAI do Conselho da União Europeia...............................65

2.3. A proposta doutrinária de criação dos Eurodelitos .................................................................. 70

2.4. A iniciativa de combate à corrupção no setor privado surgida na África: a Convenção da União Africana sobre Corrupção

2.5. A iniciativa de combate à corrupção no setor privado surgida no âmbito da Organização das Nações Unidas: a Convenção da ONU de combate à corrupção.

\section{O TRATAMENTO DISPENSADO À CORRUPÇÃO NO SETOR PRIVADO NOS} ORDENAMENTOS JURÍDICOS ESTRANGEIROS.

3.1. O crime de corrupção no setor privado no direito penal inglês.

3.1.1. O surgimento e a evolução da tipificação do crime de corrupção no setor privado no direito penal inglês

3.1.2. O atual modelo de repressão à corrupção no setor privado no direito penal inglês: considerações críticas sobre a tipicidade delitiva.

3.2. O crime de corrupção no setor privado no direito penal alemão

3.2.1. O surgimento e a evolução da tipificação do crime de corrupção no setor privado no direito penal alemão 
3.2.2. O atual modelo de repressão à corrupção no setor privado no direito penal alemão: análise crítica da tipicidade delitiva

3.3. O crime de corrupção no setor privado no direito penal francês.

3.3.1. O surgimento e a evolução da tipificação do crime de corrupção no setor privado no direito penal francês

3.3.2. O atual modelo de repressão à corrupção no setor privado no direito penal francês: análise crítica da tipicidade delitiva

3.4. O crime de corrupção no setor privado no direito penal italiano

3.4.1. O surgimento e a evolução da tipificação do crime de corrupção no setor privado no direito penal italiano.

3.4.2. O atual modelo de repressão à corrupção no setor privado no direito penal italiano: análise crítica da tipicidade delitiva

3.5. O crime de corrupção no setor privado no direito penal espanhol.

3.5.1. O surgimento e a evolução da tipificação do crime de corrupção no setor privado no direito penal espanhol

3.5.2. O atual modelo de repressão à corrupção no setor privado no direito penal espanhol: análise crítica da tipicidade delitiva

\section{OS MODELOS DE TIPIFICAÇÃO DO CRIME DE CORRUPÇÃO NO SETOR PRIVADO: CONSIDERAÇÕES SOBRE O BEM JURÍDICO TUTELADO E A NOSSA PROPOSIÇÃO SOBRE A MATÉRIA}

4.1. A lealdade e a confiança nas relações privadas como bem jurídico tutelado pelo crime de corrupção no setor privado

4.1.1. Considerações gerais sobre o modelo apontado e a proteção da lealdade e da confiança nas relações privadas na Ordem Jurídica brasileira

4.1.2. Críticas ao modelo de repressão à corrupção no setor privado ancorado na proteção da lealdade e da confiança nas relações privadas

4.2. A concorrência como bem jurídico tutelado pelo crime de corrupção no setor privado

4.2.1. Considerações gerais sobre o modelo apontado e a proteção da concorrência na Ordem Jurídica brasileira

4.2.2. Críticas ao modelo de repressão à corrupção no setor privado ancorado na proteção da concorrência...

4.3. O patrimônio como bem jurídico tutelado pelo crime de corrupção no setor privado

4.3.1. Considerações gerais sobre o modelo apontado e a proteção do patrimônio na Ordem Jurídica brasileira 
4.3.2. Críticas ao modelo de repressão à corrupção no setor privado ancorado na proteção do patrimônio

4.4. Proposta de bem jurídico a ser protegido pelo crime de corrupção no setor privado

4.4.1. A impossibilidade de criação de modelo de punição da corrupção no setor privado protetivo de todos os bens jurídicos sensíveis ao fenômeno: obrigatoriedade de escolha racional.

4.4.2. A violação da lealdade e da confiança nas relações privadas como denominador comum de toda hipótese de corrupção entre particulares

4.4.3. A impossibilidade de que a concorrência seja o objeto material imediato de proteção por tipos penais de corrupção no setor privado.

4.4.4. A insuficiência dos valores lealdade e confiança para legitimar a corrupção no setor privado: o patrimônio como objeto material central a ser protegido.

\section{PROPOSTA PARA TIPIFICAÇÃO DO CRIME DE CORRUPÇÃO NO SETOR PRIVADO NO ORDENAMENTO JURÍDICO BRASILEIRO}

5.1. Considerações gerais sobre as cautelas na elaboração de tipos penais................................206

5.2. Os elementos objetivosdos tipos penais de corrupção no setor privado ............................208

5.2.1. Os elementos objetivos da corrupção passiva no setor privado ................................208

5.2.2. Os elementos objetivos da corrupção ativa no setor privado....................................215

5.3. O elemento subjetivo do tipo penal de corrupção no setor privado....................................217

5.4. A consumação e a tentativa do crime de corrupção no setor privado.................................219

5.5. As penas do crime de corrupção no setor privado................................................................223

5.6. A natureza da ação penal do crime de corrupção no setor privado em vista do bem

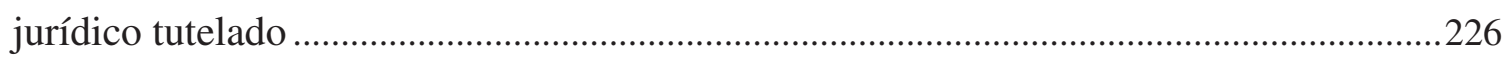




\section{INTRODUÇÃO}

O processo de formação da sociedade brasileira é marcado por inúmeros episódios, a partir dos quais é possível constatar serem os comportamentos corruptos recorrentes em nossa história. Começando no período colonial, os casos de corrupção perpassam todas as três fases da consolidação do Estado - colonial, imperial e republicana -, sendo considerados destacada razão para a existência de parte importante de nossas mazelas sociais ${ }^{1}$.

O caráter patrimonialista que caracterizou - e ainda caracteriza - o exercício do poder no Brasil $^{2}$ é fator que torna pouco precisa a definição dos limites entre os interesses públicos e os interesses privados, estes últimos, na análise precisa de HOLANDA $^{3}$, sempre colocados em patamar sobreposto àquele em que se situam os primeiros. Tal aspecto de nossa cultura conferiu ao Brasil, inclusive entre estudiosos estrangeiros, o indesejável posto de país do jeitinho ${ }^{4}$.

Necessário mencionar que o fenômeno da corrupção, na forma como classicamente é conhecido e estudado, em que pese apresente contornos de especial gravidade em nossa nação ${ }^{5}$, está presente em todas as sociedades ${ }^{6}$, desde tempos imemoriáveis ${ }^{7}$, e, em suas

\footnotetext{
${ }^{1}$ Importante mencionar, nesse diapasão, a obra de SÉRGIO HABIB, segundo o qual "a corrupção no Brasil vem de longas datas, ocorrendo em todas as três fases, a saber: colonial, imperial e republicana”. A análise de fatos históricos relevantes, feita pelo autor, dá-nos a noção de que nenhum momento de nossa trajetória passou incólume ao fenômeno da corrupção. Afinal, considera o estudioso, já na colônia, ter-se-ia implantado a "lei da vantagem, que passaria a fazer parte da cultura brasileira" (HABIB, Sérgio. Brasil: quinhentos anos de corrupção. Porto Alegre: Sergio Antonio Fabris, 1994. p. 3 e ss.).

${ }^{2}$ FAORO, Raymundo. Os donos do poder: formação do patronato político brasileiro. 3. ed. São Paulo: Globo, 2007. p. 819: "A comunidade política conduz, comanda, supervisiona os negócios, como negócios privados seus (...). Dessa realidade se projeta, em florescimento natural, a forma de poder institucionalizada num tipo de domínio: o patrimonialismo".

${ }^{3}$ Em Raízes do Brasil, HolANDA traça, com clareza, as características da formação histórico-cultural brasileira, na qual a confusão entre o público e o privado é uma constante. Aponta, nesse passo, que, "no Brasil, pode dizer-se que só excepcionalmente tivemos um sistema administrativo e um corpo de funcionários puramente dedicados a interesses objetivos e fundados nesses interesses. Ao contrário, é possível acompanhar, ao longo de nossa história, o predomínio constante das vontades particulares (...)” (HOLANDA, Sérgio Buarque de. Raízes do Brasil. 26. ed. São Paulo: Companhia das Letras, 2006. p. 145 e ss.). No mesmo sentido: WUNDERLICH, Alexandre. Dos Crimes Contra a Administração Pública. In: REALE JÚNIOR, Miguel (Coord.). Direito penal: jurisprudência em debate. Rio de Janeiro: GZ Ed., 2013. v. 4, p. 2.

${ }^{4}$ ROSENN, Keith S. The Jeito: Brazil's institutional bypass of the formal legal system and its developmental implications. The American Journal of Comparative Law, v. 19, p. 515, 1971.

${ }^{5}$ De acordo com o Corruption Perception Index, elaborado pela Transparência Internacional, no ano de 2013, o Brasil aparece apenas no $72^{\circ}$ lugar, em classificação que adota como critério o nível de percepção social do fenômeno da corrupção. TRANSPARENCY INTERNATIONAL. Corruption Perceptions Index 2013. Disponível em: <http://www.transparency.org/cpi2013/results>. Acesso em: 07 jan. 2014.

${ }^{6}$ BRIOSCHI, Carlos Alberto. Breve historia de la corrupción: de la antigüedad a nuestros días. Madrid: Taurus, 2010. p. 31.

${ }^{7}$ HUNGRIA, Nelson. Comentários ao Código Penal. 2. ed. Rio de Janeiro: Forense, 1959, v. 9, p. 365: "Deve reconhecer-se, entretanto, que a corrupção não se apresenta como um traço peculiar da época contemporânea: ela é de todos os tempos. Cita-a Montesquieu como uma das causas da queda do Império
} 
raízes, está associado a comportamentos praticados por agentes do Poder Público, que, para a satisfação de interesses pessoais, recebem vantagens indevidas como contraprestação ao exercício desviado de suas funções ${ }^{8}$.

Ocorre que, nas últimas décadas, veem-se crescer, de maneira inédita, os níveis de preocupação com outra faceta do fenômeno mencionado: a corrupção no setor privado. Constata-se que comportamentos análogos àqueles perpetrados por servidores públicos e pessoas a eles equiparadas, na celebração de pactos sceleris, de há tempos reprimidos por normas de índole criminal, são praticados, em caráter diuturno, também no âmbito de relações exclusivamente privadas, por exemplo, por administradores e funcionários de empresas ${ }^{9}$.

Com a percepção de que atos corruptivos têm o condão de prejudicar a estabilidade das relações sociais, mesmo quando não afetados os interesses primários da Administração Pública, nasce uma agenda global de discussões sobre o assunto ${ }^{10}$. A atual conjuntura econômica, as exigências do comércio global, a prevenção da delinquência internacional, a necessidade de observância às normas de governança corporativa, a transparência e a responsabilidade nos setores públicos, aliadas aos efeitos provocados pela corrupção ${ }^{11}$ seja pública, ou privada -, no âmbito de países ricos ou pobres, governos autoritários ou democracias consolidadas $^{12}$, indicam imprescindível o direcionamento ostensivo de esforços para assegurar efetivo combate à sua prática.

Romano. Atestam a sua prática os preceitos repressivos das mais antigas legislações”. No mesmo sentido: BITENCOURT, Cezar Roberto. Tratado de direito penal: parte especial. 2. ed. São Paulo: Saraiva, 2008. v. 5, p. 76.

${ }^{8}$ PRADO, Luiz Régis. A Lei $10.467 / 2002$ e os novos crimes de corrupção e tráfico de influência internacional. Revista dos Tribunais, São Paulo, v. 91, n. 803, p. 441, set. 2002.

${ }^{9}$ KINDHÄUSER, Urs. Presupuestos de la corrupción punible en el Estado, la economía y la sociedad. Los delitos de corrupción en el Código Penal alemán. Política Criminal: revista electrónica semestral de políticas públicas en materias penales, n. 3, p. 11, 2007. Disponível em: $<$ http://www.politicacriminal.cl/n_03/a_1_3.pdf>: "También en la economía puede abusarse del poder de decisión para la consecución de ventajas inconexas. La economía privada no es menos proclive a la corrupción que la Administración estatal”.

${ }^{10}$ GÓMEZ DE LA TORRE, Ignacio Berdugo; CERINA, Giorgio Dario. Sobre la corrupción entre particulares: convenios internacionales y derecho comparado. Revista Brasileira de Ciências Criminais, São Paulo, v. 89, p. 159, mar. 2011.

${ }^{11}$ CREMADES, Bernardo. Corrupción y arbitraje de inversión. Revista de Arbitragem e Mediação, São Paulo, v. 2, n. 6, p. 126, jul./set. 2005.

${ }^{12}$ MURIAL PATINO, María Victoria. Aproximación macroeconómica al fenómeno de la corrupción. In: RODRÍGUEZ GARCÍA, Nicolás; FABIÁN CAPARRÓS, Eduardo (Coords.). La corrupción en un mundo globalizado. Salamanca: Ratio Legis, 2000. p. 27. 
Destarte, amplia-se o espectro de comportamentos estudados e, ver-se-á, disciplinados pela ordem jurídica, que supõem a atuação desviada do poder, também praticados entre particulares desvinculados de cargos e funções estatais ${ }^{13}$.

No Direito europeu, mesmo antes da criação dos recentes instrumentos jurídicos internacionais e supranacionais de combate à corrupção no setor privado, a Inglaterra (1906) a Alemanha (1909) e a França (1919), já em princípios do século passado, dispunham de normas jurídicas sancionatórias que tratavam desses conflitos de interesses entre particulares. Coibiam-se comportamentos de funcionários de empresas que, buscando atender a seus anseios individuais, agiam em desconformidade com o dever de ofício que lhes era atribuído.

A incipiente, porém, elevada preocupação com a corrupção no setor privado será o objeto de análise da primeira parte desta dissertação de mestrado. Partindo da clássica noção do crime de corrupção, consubstanciado na ocorrência de pactos sceleris celebrados com a participação de agentes da Administração Pública, buscaremos chegar à atual acepção de corrupção no setor privado.

Para tanto, estudaremos as principais razões que, no entender da doutrina, fizeram com que houvesse a expansão da repressão do fenômeno corruptivo, antes adstrita às hipóteses em que figurava indivíduo atuante na esfera pública, ao bojo das relações mantidas entre particulares. Perceberemos que o incremento da complexidade das relações econômicas, consequência primeira da globalização, somado ao massivo processo de privatização de empresas públicas, característico da última década do século $\mathrm{XX}^{14}$, transpôs os entes coletivos privados para o centro dos debates jurídicos, uma vez que eles deixaram de ser mero instrumento de geração de lucros, para assumir - e isso justificaria a tipificação das condutas que serão estudadas - "graves deveres para com a coletividade em cujo meio" atuam, "respondendo às exigências do bem público e à sua função social”15.

Avaliaremos, outrossim, a interface existente entre os crimes de corrupção pública e os comportamentos que caracterizam a corrupção privada, com o propósito de aferir se a

\footnotetext{
${ }^{13}$ GÓMEZ DE LA TORRE, Ignacio Berdugo; FABIÁN CAPARRÓS, Eduardo. Corrupción y derecho penal: nuevos perfiles, nuevas respuestas. Revista Brasileira de Ciências Criminais, São Paulo, v. 81, p. 72, nov. 2009.

${ }^{14}$ ACQUAROLI, Roberto; FOFFANI, Luigi. La corruzione tra privati: note introduttive sull'esperienze italiana. In: ACQUAROLI, Roberto; FOFFANI, Luigi (Eds.). La corruzione tra privati: esperienze comparatistiche e prospettive di riforma. Milano: Giuffrè, 2003. p. 7.

${ }^{15}$ REALE JÚNIOR, Miguel. Dever de lealdade do administrador da empresa no Direito Penal. In: REALE, Miguel; REALE JÚNIOR, Miguel; REALE FERRARI, Eduardo (Orgs.). Experiências do direito. Campinas: Millennium, 2004. p. 237.
} 
criação de modelo incriminador que proíba os pactos sceleris entre particulares poderia fomentar o desenvolvimento de mais elevado nível de consciência coletiva com relação à ilicitude do fenômeno corruptivo em todas as suas variantes.

Para encerrar o capítulo inaugural do trabalho acadêmico, exporemos os argumentos dos pensadores que entendem despicienda a tipificação penal do crime de corrupção no setor privado, porquanto não haveria razão consentânea com os princípios basilares do Direito Penal que a justificasse.

Assentadas as premissas iniciais sobre os conceitos e a evolução do fenômeno estudado, verificaremos que a partir de meados da década de noventa os debates sobre a necessidade de incriminação de atos de corrupção no setor privado ganharam maior destaque. Com o aumento da complexidade das relações empresariais existentes no âmbito internacional, as condutas de desvio de poder praticadas na esfera privada deixaram de ser problema adstrito aos indivíduos nelas envolvidos, convertendo-se em situações, das quais, não raro, defluem impactos de abrangência transnacional ${ }^{16}$.

Os atos de corrupção no setor privado, aponta JAPIASSÚ, passaram a produzir efeitos cada vez mais deletérios ao desenvolvimento econômico e social, distorcendo, inclusive, a manutenção dos regulares padrões de funcionamento do mercado e gerando prejuízos para os direitos humanos ${ }^{17}$.

Nesse contexto, evidenciadas a importância da repressão às condutas de desvio de poder perpetradas entre particulares e as dificuldades enfrentadas pelos ordenamentos jurídicos nacionais na definição de políticas criminais capazes de fazê-lo, entidades internacionais e supranacionais iniciaram um processo de criação de instrumentos de Direito destinados a orientar os Estados no combate ao fenômeno da corrupção privada, os quais serão objeto do segundo capítulo da monografia ${ }^{18}$.

\footnotetext{
${ }^{16}$ GÓMEZ DE LA TORRE, Ignacio Berdugo; CERINA, Giorgio Dario. Sobre la corrupción entre particulares: convenios internacionales y derecho comparado, cit., p. 164: "Estos comportamientos llegam a alcanzar una dimensión internacional, por que sus efectos afectan a varios Estados, por la naturaleza internacional del sujeto o sujetos implicados o por la naturaleza misma de la relacción económica. La gran cuestión es establecer una política criminal adecuada para evitar estas actuaciones (...)”.

${ }^{17}$ JAPIASSÚ, Carlos Eduardo Adriano. A corrupção em uma perspectiva internacional. Revista Brasileira de Ciências Criminais, São Paulo, v. 15, n. 64, p. 322, jan./fev. 2007, p. 32.

${ }^{18}$ FOFFANI, Luigi. La corrupción en el sector privado: iniciativas internacionales y derecho comparado. Revista Brasileira de Ciências Criminais, São Paulo, v. 81, p. 81, nov. 2009: “(...) el tema de la corrupción en el sector privado ya ha sido objeto en los últimos años de una rica serie de iniciativas supranacionales, que han sido todas en la dirección de impulsar los legisladores nacionales a criminalizar este fenómeno".
} 
Proceder-se-á, então, ao aprofundado estudo dos principais instrumentos jurídicos internacionais e supranacionais que contemplam diretrizes no sentido da necessidade de repressão criminal de comportamentos de corrupção entre particulares. Tal como se demonstrará, com exceção de poucas nações europeias, a difusão da tipificação do delito em análise decorre da implementação, no âmbito dos ordenamentos jurídicos internos, dos compromissos assumidos no plano internacional.

Partindo da análise crítica da conjuntura histórica que fomentou a elaboração desses diplomas jurídicos, trataremos dos elementos neles previstos, considerados essenciais à configuração do crime de corrupção privada, aferindo os bens jurídicos tutelados, as condutas incriminadas, as sanções previstas etc..

Serão estudadas, então: a Ação Comum da União Europeia, de 22 de dezembro de 1998; a Convenção Penal Contra a Corrupção do Conselho da Europa, de 27 de janeiro de 1999; a Decisão Marco 2003/568/JAI do Conselho da Europa, de 22 de julho de 2003; a Convenção da União Africana Sobre Corrupção, de 11 de julho de 2003; e a Convenção das Nações Unidas de Combate à Corrupção, de 31 de outubro de 2003.

Por derradeiro, no capítulo segundo da dissertação, trataremos de analisar a proposta - mal sucedida -, organizada por Klaus Tiedemann, de criação dos "Eurodelitos", dentre os quais figura o crime de corrupção no setor privado.

Em sequência, no capítulo terceiro deste trabalho acadêmico, debruçar-nos-emos sobre a análise do crime de corrupção no setor privado, sob a óptica do direito comparado. Assim, com verticalidade e olhar crítico, abordaremos os mais importantes aspectos da tipicidade delitiva (histórico, bem jurídico tutelado, sujeitos do delito, comportamentos proscritos, sanções cominadas etc.) e a forma como eles recebem tratamento normativo mundo afora.

Iniciaremos o estudo com países nos quais o crime de corrupção privada é figura conhecida há anos e integra, portanto, a própria cultura jurídico-penal. Nesse grupo incluem-se a Inglaterra, a Alemanha e a França, nações europeias que, ainda em princípios do século XX, criaram figuras de repressão aos comportamentos corruptivos perpetrados no setor privado.

Outrossim, serão objeto de análise os ordenamentos jurídicos de nações que, apenas recentemente - em razão dos movimentos internacionais aludidos -, incorporaram o crime 
de corrupção privada a seus plexos normativos. Dentre elas destacaremos a Itália e a Espanha, onde há rica fonte de estudo sobre a matéria.

Como decorrência do estudo comparado empreendido, constatamos serem grandes as perplexidades existentes na definição das características basilares do crime de corrupção privada. Afinal, os modelos de repressão ao delito são extremamente variados e heterogêneos em cada nação. Nota-se existir um modelo que não diferencia corrupção no setor público e no setor privado, assentado na ideia de que o desvalor da conduta incriminada está relacionado à violação da lealdade e da confiança nas relações privadas; um modelo orientado à proteção da concorrência econômica; e, por fim, modelo patrimonialista, que castiga a corrupção privada e tem como pressuposto a ideia de violação da lealdade patrimonial entre o mandatário e o mandante ${ }^{19}$.

Feitas essas abordagens e conhecidas as características da corrupção no setor privado, bem como as dificuldades enfrentadas para a sua efetiva disciplina jurídico-penal, passaremos a avaliar, no capítulo quarto da dissertação, se é possível e necessária a introdução de tipo penal que proscreva tal modalidade delitiva no ordenamento jurídico do Brasil, país do jeitinho, e, com supedâneo nos princípios basilares do Direito Penal, tentaremos definir o(s) bem(ns) jurídico(s) que deverá(ão) ser abarcado(s) por eventual norma incriminadora.

Para alcançar esse propósito, analisaremos o tratamento constitucional conferido à lealdade nas relações privadas, à concorrência, e aos interesses patrimoniais dos empresários - que, em tese, são os bens jurídicos passíveis de serem afetados por comportamentos de corrupção entre particulares. Com mira na legislação infraconstitucional, verificaremos se essas condutas já são objeto de tratamento pelos dispositivos normativos de caráter extrapenal, bem como por preceitos legais jurídico-penais.

Do cotejo das informações coligidas faremos proposição de modelo de repressão ao fenômeno em testilha, porquanto, na esteira do pensamento de REALE JÚNIOR, entendemos necessária a criminalização da corrupção privada, cada vez mais presente na dinâmica empresarial $^{20}$. Buscaremos eleger modelo político-criminal que contemple valores dotados de dignidade constitucional, e que, em nosso sistema jurídico, confira legitimidade e eficiência à repressão do crime de corrupção no setor privado, de maneira consentânea com

\footnotetext{
${ }^{19}$ FOFFANI, Luigi. op. cit., p. 83-84.

${ }^{20}$ REALE JÚNIOR, Miguel. Dever de lealdade do administrador da empresa no Direito Penal, cit., p. 237 ss.
} 
um Direito Penal mínimo, democrático e garantidor, que não se afaste do respeito aos princípios da fragmentariedade e da subsidiariedade ${ }^{21}$.

Posteriormente, com alicerce no arcabouço doutrinário analisado e nos conhecimentos angariados sobre as diversas facetas do crime de corrupção no setor privado, buscaremos, no capítulo quinto da monografia, de lege ferenda, definir os contornos típicos do delito, propondo sua incorporação ao nosso ordenamento jurídico.

Considerando a escolha prévia do(s) bem(ns) jurídico(s) digno(s) de tutela penal, e mantendo coerência com a mesma, trataremos de todas as características que julgarmos necessárias para a descrição típica da figura delitiva de corrupção entre particulares. Assim, serão abordados os seguintes aspectos do delito: a sua natureza, os elementos objetivo-descritivos do tipo penal, os elementos objetivo-normativos do tipo penal, o elemento subjetivo do tipo penal e o seu momento consumativo.

E, para encerrar os estudos, como tentativa de emprestar contribuição efetiva ao aprimoramento de nosso sistema jurídico, elaboraremos proposta de texto legal, com a tipificação do crime de corrupção no setor privado, para encaminhamento ao Poder Legislativo nacional. Afastando os graves equívocos verificados na redação do artigo 167, do Projeto de Lei $n^{\circ}$ 236/2012, do Senado Federal, buscaremos delinear modelo de repressão de condutas que respeite os princípios básicos do Direito Penal, ao mesmo tempo em que viabilize a justa e a eficiente reprovação do delito.

No capítulo conclusivo, avocaremos os mais importantes aspectos do estudo realizado, com síntese das principais informações obtidas e conclusões alcançadas. Deixaremos evidenciada a necessidade de que contemplemos, em nosso plexo normativo punitivo, o crime de corrupção no setor privado e exporemos a conformação típica que, em nosso entender, a novel figura delitiva deverá ostentar.

\footnotetext{
${ }^{21}$ PORTO, Luiz Guilherme Moreira. Tipicidade nos crimes de falsidade documental em face do bem jurídico protegido. 203 f. Dissertação (Mestrado em Direito) - Faculdade de Direito, Universidade de São Paulo, São Paulo, 2002. p. 2.
} 
Todavia, as peculiaridades do cenário em que as situações de prática de atos de corrupção no setor privado ocorrem, qual seja, o ambiente empresarial, podem fazer com que, não raro, a persecução penal de tais comportamentos, em vez de favorecer a proteção do patrimônio dos entes privados, potencialize os prejuízos decorrentes da celebração de pactos sceleris.

Conforme bem esclarece REALE JÚNIOR, pode "ocorrer eventual interesse da empresa em não promover a persecução penal, tendo em vista os efeitos nocivos da publicidade da corrupção praticada por um dirigente ${ }^{, 715}$, circunstância que deve ser considerada na definição dos elementos essenciais do delito estudado.

Pense-se, para exemplificar, no caso de uma pessoa jurídica de direito privado de capital aberto que tome conhecimento de negociações ilícitas conduzidas por seus funcionários. Mediante o recebimento de vantagens indevidas de fornecedores, eles adquirem matérias-primas a preço mais elevado do que o praticado no mercado e que seriam utilizadas no desenvolvimento de novas tecnologias. Atribuindo-se aos órgãos públicos a obrigação ex officio de persecução penal desse comportamento, informações empresariais confidenciais, que, mantidas em sigilo, poderiam dar origem a novas tecnologias e a altos lucros para a empresa, podem acabar expostas aos concorrentes.

Destarte, em certas hipóteses, além de inviabilizar a conclusão de projetos tecnológicos lucrativos e, por conseguinte, o aumento patrimonial que deles seria decorrente, a difusão de informação sobre a prática de atos corruptivos no âmbito empresarial pode criar um ambiente de desconfiança no mercado. Com isso, é possível que haja redução do valor do capital acionário das pessoas jurídicas afetadas: em tais casos, inconteste que a persecução penal pública da corrupção no setor privado seria desastrosa para a empresa e para os seus investidores.

Idêntica é a situação da empresa que descobre que seus colaboradores estão transferindo a um concorrente seu, como contraprestação pelo recebimento de vantagens indevidas, informações confidenciais sobre os dados de seus clientes e condições de

(artigo 155), roubo (artigo 157), extorsão (artigos 158, 159 e 160), algumas modalidades de usurpação (artigo 161 e 162), algumas modalidades de dano (artigo 163, 165 e 166), apropriação indébita (artigos 168, 168-A e 169), todas as modalidades de estelionato (artigos 171, 172, 173, 174 e 175), outras modalidades de condutas fraudulentas (artigos 177 e 178) e a receptação (artigo 180). Por outro lado, são crimes de iniciativa pública sujeitos à representação o furto de coisa comum (artigo 156) e a fraude, prevista no artigo 176.São de iniciativa privada, apenas, algumas espécies de usurpação (artigo 161, §3º), de dano (artigo 163, caput e parágrafo, inciso IV e 164) e a fraude à execução (artigo 179).

${ }^{715}$ REALE JÚNIOR, Miguel. Dever de lealdade do administrador da empresa no Direito Penal, cit., p. 246. 
negociações com eles mantidas. Fosse de iniciativa pública incondicionada a persecução penal desse comportamento, a empresa prejudicada com a celebração dos pactos sceleris seria impelida a fornecer para todos os indivíduos implicados na dinâmica processual os dados estratégicos de seu negócio, situação que a colocaria em posição de ainda maior vulnerabilidade.

Problemas surgiriam, também, nas situações em que as pessoas jurídicas de direito privado tomassem conhecimento de que o seu melhor funcionário, maior especialista em sua área de atuação, estaria praticando atos de corrupção no setor privado. Nesse caso, se a ação penal fosse iniciada pelo Ministério Público, de ofício, a empresa acabaria forçada a romper os vínculos relacionais com o agente que recebesse as vantagens indevidas, malgrado solucionar a questão internamente, com a preservação do vínculo empregatício, pudesse ser mais vantajoso sob o viés econômico.

Por conseguinte, não obstante inquestionável a relevância dos bens jurídicos que podem ser afetados com a prática de atos de corrupção no setor privado, verifica-se que atribuir aos órgãos públicos a incumbência de persecução penal do fenômeno, sem que haja concordância da vítima, pode favorecer o agravamento das consequências que surgem como desdobramento da celebração de acordos ilícitos entre particulares, em vez de promover a proteção do patrimônio das entidades privadas.

Destarte, como forma de equacionar esses problemas, assegurando a efetiva tutela do patrimônio do setor privado, defende-se que a condução dos procedimentos criminais destinados à punição da corrupção entre particulares seja feita pelos órgãos públicos. Contudo, a sua atuação será condicionada à representação formal da vítima ${ }^{716}$ : trata-se, pois, de crime de ação pública condicionada.

\footnotetext{
${ }^{716}$ MARQUES, José Frederico. Elementos de direito processual penal. 3. atual. Campinas: Millennium, 2009. v. 1, p. 296: “A ação penal pública condicionada pode depender de representação do ofendido nos casos taxativamente previstos em lei. Embora o crime atinja um bem jurídico, cuja tutela penal interessa precipuamente ao Estado, figuras delituosas existem em que a pretensão punitiva somente surge quando o sujeito privado, que desse bem jurídico é titular, também tenha interesse na punição da infração penal (...). A representação é uma delatio criminis postulatória (...) destinada a produzir determinado efeito jurídico, ou seja, a provocar o desencadeamento da persecução penal". No mesmo sentido: TOURINHO FILHO, Fernando da Costa. Processo penal. 30. ed. São Paulo: Saraiva, 2008. v. 1, p. 328.
} 


\section{CONCLUSÕES ${ }^{717}$}

1.1. O vocábulo corrupção tem origem na expressão latina corruptio e está relacionado às noções de deterioração, devassidão, podridão e perversão. Antes de ser incorporado ao universo jurídico, já fazia parte do léxico de outros ramos das ciências sociais, que o empregavam para tratar de situações recorrentes no seio social, caracterizadas pelo exercício desviado do poder.

1.2. No Direito Penal, o vocábulo corrupção usualmente é utilizado para fazer alusão ao exercício abusivo de poderes: a corrupção está atrelada a relações jurídicas legítimas, que vinculam um sujeito investido de poderes especiais (intraneus) a outro sujeito (principal), que lhe outorga tais poderes, em benefício do qual eles devem ser exercidos.

1.3. Nas situações em que há prática de comportamentos corruptos, o indivíduo que ostenta posição jurídica qualificada, diante de conflito de interesses com o principal, é movido a desempenhar as suas funções de forma desviada. Impelido a optar entre agir em conformidade com as obrigações que lhe são atribuídas e tentar obter benefício indevido mediante o descumprimento de seus deveres, o agente escolhe a segunda opção: denominase corrupção passiva a solicitação ou o recebimento de vantagem indevida pelo intraneus, em detrimento do principal.

1.4. Tais comportamentos acontecem, em regra, porque sujeito estranho à relação principal-agente nela busca se imiscuir, perseguindo objetivos próprios, também conflitantes com os interesses do principal, e passíveis de serem alcançados com o exercício abusivo dos poderes outorgados ao intraneus. Emerge, então, a figura do corruptor, que atua mediante promessas, oferecimentos ou doações de vantagem indevida ao corrupto - corrupção ativa -, buscando influenciá-lo a agir em desconformidade com as obrigações inerentes aos poderes dos quais é mandatário.

1.5. Tradicionalmente, a celebração de pactos sceleris dispunha de relevância penal apenas nas hipóteses em que o corrupto fosse funcionário da Administração Pública ou apresentasse condição jurídica a essa equiparada.

\footnotetext{
${ }^{717} \mathrm{Na}$ numeração destas conclusões, o primeiro algarismo indica o capítulo do trabalho do qual extraída a afirmação, e, o seguinte, a sequência das conclusões de cada capítulo.
} 
1.6. Nas últimas décadas, contudo, intensificaram-se as discussões sobre a necessidade de tipificação penal da corrupção privada: a gravidade do fenômeno corruptivo e o aumento das situações em que é verificado; a verticalização da globalização, com o aumento da complexidade da dinâmica econômica empresarial; os processos de privatização; a interface entre os pactos sceleris na Administração Pública e aqueles celebrados por particulares; e a ineficiência das normas extrapenais são algumas das razões a recomendar a implementação de política criminal sobre o assunto.

1.7. A preocupação com a corrupção no setor privado, acompanhada da disseminação de normas jurídico-penais mundo afora que a tipificam, não obstante defendida por importantes penalistas que se dedicam ao assunto, é criticada por doutrinadores de relevo, para os quais o Direito Penal não tem sido empregado de forma adequada para fazer frente à repressão do fenômeno: haveria, com a tipificação do delito, violação dos princípios da ultima ratio, da subsidiariedade e da fragmentariedade.

2.1. Nos âmbitos supranacional e internacional, a preocupação com a corrupção iniciou-se em 1977, quando os Estados Unidos criaram o Foreing Corrupt Practices Act, instrumento repressivo cujo escopo era penalizar as empresas norte-americanas que praticassem atos de corrupção de funcionários públicos estrangeiros. Apenas hipóteses de corrupção de agentes estatais eram objeto de disciplina jurídica.

2.2. A partir de 1998, foram criados diversos instrumentos jurídicos supranacionais e internacionais orientados à punição da corrupção no setor privado. Entretanto, é bastante variado o tratamento dispensado por cada um deles ao fenômeno.

2.3. A Ação Comum 98/742/JAI da União Europeia foi o primeiro instrumento jurídico supranacional dedicado ao combate à corrupção no setor privado, que deveria ser sancionada com vistas à proteção da lealdade concorrencial. Todavia, o texto continha deficiências graves na descrição das condutas de pactos sceleris e, malgrado tenha fomentado discussões sobre o fenômeno, surtiu parcos efeitos concretos, em razão da inexistência de mecanismos que impusessem sua implementação.

2.4. Poucos meses após o advento da Ação Comum, o Conselho da Europa criou a Convenção Penal Sobre a Corrupção, em janeiro de 1999, reforçando a tendência de direcionamento de atenção aos pactos sceleris privados. À diferença do que ocorria no texto comunitário então vigente, a corrupção entre particulares era pensada como fonte de violação dos deveres de lealdade e de confiança nas relações privadas. O rol de sujeitos 
ativos do crime de corrupção passiva contemplado no texto abarcava não apenas trabalhadores regularmente atrelados a uma determinada pessoa jurídica, mas, de igual modo, os advogados, os agentes externos, os assessores e quaisquer outros indivíduos com os quais existisse uma relação pautada nos interesses do principal.

2.5. A Decisão Marco 2003/568/JAI do Conselho da União Europeia substituiu a Ação Comum 98/742/JAI, mantendo inalterada a ideia de que a corrupção privada deveria ser sancionada para proteger a livre e leal concorrência. Pondo-se miras nos contornos típicos das condutas que caracterizariam a corrupção no setor privado, é possível constatar que a tentativa de definir comportamentos atentatórios à regularidade concorrencial foi malsucedida, pois não foram abarcadas pelo texto diversas situações das quais deflui lesão concreta a tal interesse jurídico. Em verdade, para a configuração da prática delitiva, nos moldes previstos no texto comunitário, impõe-se concomitante violação da concorrência e da lealdade no setor privado (pluriofensivo). Apesar das deficiências verificadas no texto normativo, o advento da Decisão Marco estimulou diversas reformas legislativas nos Estados-membros da União Europeia.

2.6. Também em 2003, foi criada a Convenção de Combate à Corrupção no Setor Privado da União Africana, na qual foram inseridos modelos de incriminação do fenômeno voltados à proteção da lealdade dos agentes privados. Entretanto, são graves as falhas de técnica legislativa existentes no texto internacional, que não gerou impacto relevante na ordem jurídica das nações do continente em que fora criado.

2.7. O mais abrangente e completo instrumento internacional de combate à corrupção é a Convenção da ONU de Combate à Corrupção, que faz parte do ordenamento jurídico brasileiro. Nela, recomenda-se a criação de normas penais voltadas ao combate aos atos de corrupção perpetrados no setor privado, capazes de afetar a integridade e a honestidade nas atividades econômicas, financeiras e comerciais. Não foi direcionada preocupação específica com a proteção da concorrência: privilegiaram-se a lealdade e a confiança nas relações privadas. A implementação da Convenção da ONU é fator importante para a disseminação da ideia de que o crime de corrupção no setor privado deve ser objeto de reprimenda criminal. Porém, melhores seriam os resultados alcançados, se o texto internacional previsse obrigatória a tipificação do fenômeno. 
2.8. O crime de corrupção no setor privado foi inserido também na proposta dos Eurodelitos. Analisando-se modelo incriminador elaborado, é possível concluir que a punição do fenômeno deveria ser feita com vistas a assegurar que a atuação dos agentes econômicos não interferisse de forma artificial no regular funcionamento dos mercados baseados na livre concorrência. Não obstante elaborada por importantes juristas de diversas instituições de ensino europeias, foram reduzidos os impactos decorrentes da proposta, que não interferiu de forma significativa nos processos de criação legislativa.

3.1. Nos ordenamentos jurídicos estrangeiros, da mesma maneira, é bastante heterogêneo o tratamento dispensado ao fenômeno da corrupção no setor privado. Podemse destacar ao menos três distintos modelos de política criminal de combate ao fenômeno. Por essa razão, foram analisados os dispositivos incriminadores existentes na Inglaterra, na Alemanha, na França, na Itália e na Espanha.

3.2. A Inglaterra foi o primeiro país a criar preceitos legais incriminadores dos pactos sceleris entre particulares (1906). Não se estabeleceu qualquer distinção no tratamento jurídico da corrupção de agentes públicos e da corrupção privada, situação preservada no Bribery Act 2010. Com vistas à proteção da lealdade e da confiança nas relações privadas, estabeleceu-se idêntico tratamento ao indivíduo, funcionário público ou não, que realizasse acordos corruptivos. Tal situação gera desequilíbrios no ordenamento jurídico britânico, pois comportamentos que apresentam graus de gravidade muito distintos acabam punidos com sanções penais de idêntico - e elevado - patamar.

3.3. Na Alemanha também foi precoce a tipificação da corrupção no setor privado (1909), antes prevista em diploma normativo dedicado à proteção da lealdade concorrencial. Atualmente, os atos corruptivos privados estão inseridos no artigo $\$ 299$ do Código Penal tedesco (StGB), ainda inspirado na ideia de que é necessário coibi-los para a salvaguarda da concorrência. Todavia, há falhas graves no dispositivo legal de tipificação do delito. Entretanto, o modelo político-criminal alemão é o que mais tem influenciado a tipificação dos pactos corruptivos privados mundo afora.

3.4. O legislador ordinário francês, a exemplo dos ingleses e alemães, não tardou em criar modelo de punição para os pactos sceleris privados. Inicialmente, foram tipificados para que a distribuição de bens escassos não sofresse interferências indevidas (1919). Posteriormente, a preocupação foi dirigida à salvaguarda das relações laborais (1994), o que justificou a incorporação do delito ao Código de Trabalho. Por fim, a partir de 2005, o crime foi reinserido no Código Penal, com o propósito declarado de proteção da 
concorrência. Porém, em que pese a tentativa, as falhas no processo de elaboração legislativa acabaram fazendo com que poucas modificações fossem percebidas no tocante às condutas proibidas, que não se coadunam com a ideia de que é a higidez dos mercados o bem jurídico tutelado. Remanescem comportamentos que afetam primacialmente a lealdade nas relações laborais, o que deixa mostras claras das dificuldades na elaboração dos tipos penais de punição do fenômeno.

3.5. A Itália apenas tipificou a corrupção no setor privado no ano de 2002: na ordem jurídica italiana, centra-se o desvalor dos comportamentos corruptos privados nos prejuízos econômicos que eles podem gerar. Apenas a celebração de pactos sceleris que culminem com redução patrimonial do principal se enquadra no modelo de conduta proibida. Tal opção contraria os textos comunitários de combate à corrupção no setor privado, o que tem feito surgir críticas na Europa sobre o trabalho do legislador italiano.

3.6. A Espanha é nação em que a pressão internacional para a criação de normas de combate à corrupção privada surtiu efeito concreto. A partir de reforma legislativa operada em 2010, criou-se a possibilidade de punição criminal dos pactos sceleris entre particulares, com inspiração na Decisão Marco 2003/568/JAI. Com efeito, na exposição de motivos da legislação vigente, afirma-se que é a concorrência leal o objeto material de proteção pelo artigo 286 bis do Código Penal. Entretanto, o tipo penal criado condiciona a consumação delitiva à criação de risco concomitante à concorrência e à lealdade que une o intraneus e o principal. Há, por conseguinte, grande dificuldade na elaboração de tipo penal destinado à punição da corrupção privada, seja por motivo da definição dos bens jurídicos tutelados, seja em razão da problemática relativa à especificação dos comportamentos proibidos.

4.1. O modelo de política criminal de combate à corrupção no setor privado voltado à proteção da lealdade e da confiança nas relações privadas está presente em nações como Inglaterra, França, Bélgica, Suécia, Japão e Coreia do Sul. Com efeito, o referido objeto material é dotado de importância jurídica impassível de contestação e, na ordem jurídica brasileira, é contemplado em dispositivos normativos de caráter extrapenal e penal. Todavia, criar norma penal com o desiderato de proteger tão somente a lealdade e a confiança no setor privado pode significar sacrifício ingente dos princípios de limitação do poder punitivo estatal. Apenas para exemplificar, o postulado da ultima ratio ficaria prejudicado, pois pode ser que eventual tipo penal sirva para fixar parâmetros morais de funcionamento do mercado, com o que o Direito Penal não deve se ocupar; e o princípio da 
legalidade poderia ser violado, pois não há definição precisa do que é ser leal ou não, nas atividades econômicas. Ademais, tal modelo torna difícil legitimar a punição do corruptor, que, no mais das vezes, não tem obrigações para com o principal.

4.2. O modelo que entende devam ser os pactos sceleris privados sancionados para a proteção da higidez dos mercados competitivos é o que com mais frequência tem sido considerado no momento de tipificação do fenômeno. Presente em países como a Alemanha, Suíça e República Tcheca, o aludido modelo é orientado à proteção de objeto material fundamental para o regular desenvolvimento econômico e recebe, na ordem jurídica brasileira, atenção de normas constitucionais e infraconstitucionais, extrapenais e penais. Entretanto, também esse modelo pode ser incompatível com os princípios basilares do Direito Penal. Além de impossível determinar com precisão qual é o limite entre comportamentos desleais e leais, dificilmente os atos de corrupção privada têm potencialidade para afetar a concorrência em grau tal que justifique a incidência de preceitos incriminadores. Ademais, sendo esse o bem jurídico tutelado, deverão ser considerados irrelevantes penais diversas espécies de pactos sceleris, as quais, malgrado não interfiram na concorrência, podem provocar consequências deletérias para outros importantes bens jurídicos.

4.3. Por fim, há modelo de sancionamento penal da corrupção entre particulares orientado à proteção do patrimônio dos agentes privados, contemplado na Itália e na Áustria. Busca-se, com esse modelo, a proteção de bem jurídico fundamental, que está inserido no núcleo duro do Direito Penal, o que evita perquirições relativas à sua dignidade penal. Ademais, é possível que sejam definidos com maior precisão os comportamentos proibidos, porquanto a celebração de acordos delitivos ostentará relevância penal se fizer surgir prejuízo patrimonial concreto para o principal.

4.4. Em nossa opinião, o fenômeno da corrupção no setor privado pode afetar diversos bens jurídicos, dentre os quais, a lealdade concorrencial, a lealdade e a confiança que conferem suporte às relações entre particulares e o patrimônio. Entretanto, há obstáculos intransponíveis para que todos eles sejam tutelados por meio da criação de apenas um tipo penal. Afinal, se a configuração da prática delitiva depender de simultânea violação dos mesmos, jamais poderão ser considerados relevantes os mais recorrentes pactos sceleris da vida real, que dificilmente atingem a todos esses bens essenciais. 
4.5. Considerada a estrutura da corrupção, é possível concluir ser elemento obrigatório em qualquer tipo penal orientado à punição do fenômeno, que os valores de lealdade e confiança, mesmo que em plano secundário, sejam contemplados: a violação do aludido bem jurídico, ou, pelo menos, a sua colocação em situação de perigo, é denominador comum de toda hipótese de corrupção entre particulares.

4.6. Todavia, promover o sancionamento da corrupção entre particulares com vistas a assegurar tão somente que os agentes do setor privado atuem em consonância com as obrigações por eles assumidas perante os seus respectivos principais não seria consentâneo com os princípios da ultima ratio e da subsidiariedade, que são fontes inafastáveis de limitação do ius puniendi estatal.

4.7. Por isso, entendemos devam ser criados tipos penais que assegurem a proteção da lealdade e da confiança que esteiam as relações privadas, e, ao mesmo tempo, do patrimônio dos agentes do setor privado, bem jurídico fundamental, capaz de conferir concretude e legitimidade às normas de proibição dos pactos sceleris privados.

4.8. Tem-se que a corrupção privada é fenômeno que deve ser tipificado por normas de índole criminal, não com a finalidade de proteção da regularidade do funcionamento da concorrência econômica, mas para que sejam resguardadas a lealdade e a confiança que amparam as relações entre particulares, dado elementar de toda hipótese corruptiva, e, principalmente, o patrimônio privado, bem jurídico essencial, que não se pode admitir seja violado, tanto em razão dos interesses imediatos dos seus titulares, quanto em razão da necessidade de que ele cumpra a sua relevante e constitucional função social.

5.1. Diante dessas considerações, propomos a criação de tipos penais de corrupção passiva e ativa no setor privado, nos moldes a seguir apresentados:

Corrupção passiva:

Praticar ou omitir, administrador ou empregado de pessoa jurídica de direito privado, mediante promessa ou recebimento de vantagem indevida, para si ou para outrem, ato contrário às suas obrigações funcionais, do que resulte prejuízo à entidade.

Pena: reclusão, de 01 (um) a 04 (quatro) anos, e multa.

$\S 1^{\circ}$. A pena aumenta-se de um terço, se o crime é praticado contra pessoa jurídica de direito privado que seja sociedade anônima aberta, nos termos da legislação vigente.

$\S 2^{\circ}$. Somente se procede mediante representação. 
Corrupção ativa no setor privado:

Oferecer, prometer ou entregar, visando à obtenção de benefício para si ou para outrem, vantagem indevida a administrador ou empregado de pessoa jurídica de direito privado, para que pratique ou omita ato contrário às suas obrigações funcionais, do que resulte prejuízo à entidade.

Pena: reclusão, de 01 (um) a 04 (quatro) anos, e multa.

$\S 1^{\circ}$. A pena aumenta-se de um terço, se o crime é praticado contra pessoa jurídica de direito privado que seja sociedade anônima aberta, nos termos da legislação vigente.

$\S 2^{\circ}$. Somente se procede mediante representação. 


\section{REFERÊNCIAS}

ABANTO VÁSQUEZ, Manuel. Delitos contra el mercado, viejas prácticas, nuevas figuras: delitos contra la libre y leal competencia. In: SERRANO-PIEDECASAS, José Ramón; DEMÉTRIO CRESPO, Eduardo (Dir.). Cuestiones actuales de derecho penal empresarial. Madrid: Colex, 2010.

ACCIOLY, Hildebrando; SILVA, G.E. do Nascimento; CASELLA, Paulo Borba. Manual de direito internacional público. 16. ed. São Paulo: Saraiva, 2008.

ACQUAROLI, Roberto; FOFFANI, Luigi. La corruzione tra privati: note introduttive sull'esperienze italiana. In: ACQUAROLI, Roberto; FOFFANI, Luigi (Eds.). La corruzione tra privati: esperienze comparatistiche e prospettive di riforma. Milano: Giuffrè, 2003.

ALLDRIGE, Peter. Reforming the criminal law of corruption. Criminal Law Forum, v. 11, n. 3, p. 287-322, 2000.

ÁLVARES GARCÍA, Javier. Derecho penal español: parte especial. Valencia: Tirant lo Blanch, 2011. v. 2.

AMARAL JÚNIOR, Alberto do. Introdução ao direito internacional público. São Paulo: Atlas, 2008.

ANDREAZA, Gastone; PISTORELLI, Luca. Novità legislative: 1. 6 novembre 2012, n. 190 recante "Disposizione per la prevenzione e la repressione della corruzione e dell'illegalità nella pubblica amministrazione", Roma, novembro de 2012. Disponível em: CORTE SUPREMA DI CASSAZIONE. Disponível em: $<$ http://www.cortedicassazione.it/Documenti/Relazione_III_11_12.pdf>. CORTE SUPREMA DI CASSAZIONE. Disponível em: $<$ http://www.cortedicassazione.it/Documenti/Relazione_III_11_12.pdf>. Acesso em: 24 fev. 2013.

ARENA, Maurizio. La corruzione tra privati: le responsabilità di persone fisiche e società. Bologna: Filodiritto Ed., 2012.

ARGANDOÑA, Antonio. La Convención de las Naciones Unidas contra la Corrupción y su impacto sobre las empresas internacionales. IESE Business School - Universidad de Navarra, Documento de Investigación DI n. 656, Navarra, oct. 2006. 
ARROYO ZAPATERO, Luis. La armonización internacional del derecho penal. In: CONGRESSO INTERNACIONAL: POLÍTICA CRIMINAL EN LA ERA DE LA DECLARACIÓN DEL MILENIO DE LAS NACIONES UNIDAS, 16. 2012, México. Cahiers de Defense Sociale. Cuenca: UCLM, 2012.

; NIETO MARTÍN, Adán. Fraude y corrupción en el derecho económico europeo. In: ARROYO ZAPATERO, Luis; NIETO MARTÍN, Adán (Coords.). Fraude y corrupción en el derecho penal económico europeo: eurodelitos de corrupción y fraude. Cuenca: Ediciones de la Universidad Castilla-la Mancha, 2006.

BACIGALUPO, Enrique. Compliance y derecho penal. Pamplona: Aranzadi, 2011.

BAPTISTA, Luiz Olavo. Contratos internacionais. 1. ed. São Paulo: Lex Magister, 2011.

BECCARIA, Cesare. Dos delitos e das penas. Trad. José de Faria Costa. São Paulo: Calouste Gulbenkian, 1998.

BENITO SÁNCHEZ, Demelsa. El delito de corrupción en las transacciones comerciales internacionales. Salamanca: Iustel, 2012.

; CERINA, Giorgio Diogo. Apuntes sobre los delitos de corrupción: problemas actuales y perspectivas de reforma. In: DÍAZ SANTOS, María del Rosario; METALLANES RODRÍGUES, Nuria; FABIÁN CAPARRÓS, Eduardo (Coords.). De los delitos y de las penas, hoy: la nueva reforma del Código Penal. Salamanca: Ratio Legis, 2009.

BITENCOURT, Cezar Roberto. Tratado de direito penal: parte especial. 4. ed. São Paulo: Saraiva, 2008. v. 3.

Tratado de direito penal: parte especial. 2. ed. São Paulo: Saraiva, 2008. v. 5.

Tratado de direito penal: parte especial. 3. ed. São Paulo: Saraiva, 2009. v. 5.

. Tratado de direito penal: parte geral. 13. ed. São Paulo: Saraiva, 2008. v. 1.

; SCHIMIDT, Andrei Zenkner. Direito penal econômico aplicado. Rio de Janeiro:

Lúmen Juris, 2004.

BLANCO CORDERO, Isidoro. La reforma de los delitos de corrupción mediante la Ley Orgánica 5/2010: nuevos delitos y aumento de penas. Diario la Ley, Madrid, Sección Tribuna, ano 31, n. 7534, 23 dez. 2010.

BRIOSCHI, Carlos Alberto. Breve historia de la corrupción: de la antigüedad a nuestros días. Madrid: Taurus, 2010. 
BUERBA PANDO, Adriana. El delito de corrupción entre particulares. Disponível em: $<$ http://www.perezllorca.com/eses/SalaDePrensa/Articulos/15032011_ABP\%20\%20TAH.Pdf>. Acesso em: 22 jan. 2013.

CABEZA OLMEDA, Araceli Manjón; VENTURA PÜSCHEL, Arturo (Orgs.). Derecho penal español: parte especial (II). Valencia: Tirant lo Blanch, 2011.

CALDERONE, Carmelo Renato. Lotta alla corruzione in campo comunitário ed Internazionale. Rivista Trimestrale di Diritto Penale Dell'Economia, Padova, v. 14, n. 3, lugl./sett. 2001.

CAMARGO, Beatriz Corrêa. Instrumentos internacionais no combate à corrupção: transformações e harmonização do direito penal brasileiro - considerações sobre os crimes praticados por particular contra a administração pública estrangeira. Revista Brasileira de Ciências Criminais, São Paulo, v. 19, n. 89, mar./abr. 2011.

CAPPIELLO, Cristina. La corruzione privata. Dissertação de Mestrado apresentada à Universidade Luiss Guido Carli, Roma, 2009.

CARBAJO CASCÓN, Fernando. Corrupción pública, corrupción privada y derecho privado patrimonial: una relación instrumental. Uso perverso, prevención y represión. In: RODRÍGUEZ GARCÍA, Nicolás; FABIÁN CAPARRÓS, Eduardo (Coords.). La corrupción en un mundo globalizado: análisis interdisciplinar. Salamanca: Ratio Legis, 2004.

CARLETTI, Elio. La corruzione nel settore privato tra tutela penale e sanzioni civili. In: ACQUAROLI, Roberto; FOFFANI, Luigi (Eds.). La corruzione tra privati: esperienze comparatistiche e prospettive di riforma. Milano: Giuffrè, 2003.

CAVALIERI FILHO, Sérgio. Programa de responsabilidade civil. 8. ed. São Paulo: Atlas, 2008.

COELHO, Fábio Ulhôa. Curso de direito comercial: direito de empresa. 16. ed. São Paulo: Saraiva, 2012. v. 2.

COOTER, Robert; ULEN, Thomas. Direito e economia. 5. ed. Porto Alegre: Bookman, 2010 .

COSTA, Helena Regina Lobo da. Corrupção na história do Brasil: reflexões sobre suas origens no período colonial. In: DEL DEBBIO, Alessandra; MAEDA, Bruno Carneiro; AYRES, Carlos Henrique (Coords.). Temas de anticorrupção e compliance. Rio de Janeiro: Elsevier, 2013. 
COUNCIL OF EUROPE. Criminal Law Convention on Corruption (Explanatory Report). Disponível em: <http://conventions.coe.int/Treaty/en/Reports/Html/173.htm>. Acesso em: 08 ago. 2013.

Disponível em: <http://www.coe.int/aboutCoe/index.asp?page=nosObjectifs\&l=en>. Group of States against corruption (GRECO). Disponível em:
$<$ http://www.coe.int/t/dghl/monitoring/greco/default_en.asp $>$.

CREMADES, Bernardo. Corrupción y arbitraje de inversión. Revista de Arbitragem e Mediação, São Paulo, v. 2, n. 6, p. 126-142, jul./set. 2005.

DE ANGELIS, Paolo; JANNONE, Angelo. D.L. Anticorruzione: la corruzione tra privati e la tentazione del panpenalismo. Cosa cambia nel modello. Rivista de la Responsabilità Amministrativa delle Società e degli Enti, Roma, n. 4, ott./dic. 2012.

DE LA CUESTA, José Luis. Armonización penal en la Unión Europea. In: ANDRADE, Manuel da Costa; ANTUNES, Maria João; SOUSA, Susana Aires de (Orgs.). Estudos em Homenagem ao Prof. Doutor Jorge Figueiredo Dias. Coimbra: Coimbra Ed., 2010. v. 1.

Iniciativas internacionales contra la corrupción. Caderno del Instituto Vasco de Criminología, San Sebastián, n. 17, 2003.

; BLANCO CORDERO, Isidoro. La criminalización de la corrupción en el sector privado: asignatura pendiente del derecho penal español? In: DÍEZ RIPOLLÉS, J. L.; ROMEO CASABONA, C. M.; GRACIA MARTÍN, L.; HIGUERA GUIMERÁ, J. F, (Eds.). La ciencia del derecho penal ante el nuevo siglo: libro homenaje al Profesor Dr. Don José Cerezo Mir. Madrid: Tecnos, 2002.

; L La criminalizzazione della corruzione nel settore privato: aspetti sovranazionali e di diritto comparato. In: ACQUAROLI, Roberto; FOFFANI, Luigi (Eds.). La corruzione tra privati: esperienze comparatistiche e prospettive di riforma. Milano: Giuffrè, 2003.

DE NICOLA, Alessandro; CAPPIELLO, Laura; ROTUNNO, Ivan. La corruzione tra privati: approfondimenti. Corporate Law Alert, Ott. 2012. Disponível em: $<$ http://www.orrick.com/_layouts/DownloadDocument.aspx?ID=S7EY4QEKY5FT-17813507>. Acesso em: 23 fev. 2013.

DELMANTO, Celso. Código Penal comentado. 8. ed. Rio de Janeiro: Renovar, 2000.

DÍEZ RIPOLLÉS, José Luis. A racionalidade das leis penais: teoria e prática. São Paulo: Ed. Revista dos Tribunais, 2005. 
DOLCINI, Emilio; FRANCESCO, Vigano. Sulla riforma in cantiere dei delitti di corruzione. Diritto Penale Contemporaneo, Milano, n. 1, apr. 2012.

ENGLE, Eric. I get by with a little help from my friends? Understanding the U.K. AntiBribery Statute, by reference to the OECD Convention and the Foreign Corrupt Practices Act. The International Lawyer, American Bar Association, v. 44, p. 1173-1188, 2011. Disponível em: <http://ssrn.com/abstract=1702470>.

ESPAÑA. PODER JUDICIAL. Consejo General del Poder Judicial. Disponível em: $<$ http://webcache.googleusercontent.com/search?q=cache:jp6Aq0xrbcJ:www.poderjudicial.es/stfls/CGPJ/COMISI\%C3\%93N\%2520DE\%2520ESTUDIOS\%2 520E\%2520INFORMES/INFORMES\%2520DE\%2520LEY/DOCUMENTOSCGPJ/Infor me\%2520anteproyecto $\% 2520$ modificacion $\% 2520$ Codigo $\% 2520$ Penal.pdf $+\& \mathrm{~cd}=1 \& \mathrm{hl}=\mathrm{pt}-$ BR\&ct=clnk\&gl=br>. Acesso em: 03 fev. 2014.

FAORO, Raymundo. Os donos do poder: formação do patronato político brasileiro. 3. ed. São Paulo: Globo, 2007.

FARALDO CABANA, Patrícia. Hacia un delito de corrupción en el sector privado. Estudios Penales y Criminológicos, Santiago, n. 23, 2001.

FERRAJOLI, Luigi. Direito e razão: teoria do garantismo penal. 2. ed. São Paulo: Ed. Revista dos Tribunais, 2006.

FERREIRA FILHO, Manoel Gonçalves. Curso de direito constitucional. 32. ed. São Paulo: Saraiva, 2006.

FLORE, Daniel. L'incrimination de la corruption: les nouveaux instruments internationaux. la nouvelle loi belge du 10 février 1999. Bruxelas: La Charte, 1999.

FOFFANI, Luigi. La corruzione fra privati nel nuovo diritto penale societario: un primo passo a un'occasione mancata? In: ACQUAROLI, Roberto; FOFFANI, Luigi (Eds.). La corruzione tra privati: esperienze comparatistiche e prospettive di riforma. Milano: Giuffrè, 2003.

La corrupción en el sector privado: iniciativas internacionales y derecho comparado. Revista Brasileira de Ciências Criminais, São Paulo, v. 81, nov. 2009.

FORTI, Gabrio. La corruzione tra privati nell'orbita di disciplina della corruzione pubblica: un contributo di tematizzazione. In: ACQUAROLI, Roberto; FOFFANI, Luigi (Eds.). La corruzione tra privati: esperienze comparatistiche e prospettive di riforma. Milano: Giuffrè, 2003.

GARCÍA MEXÍA, Pablo. Los conflictos de intereses y la corrupción contemporánea. Pamplona: Aranzadi, 2001. 
GILI PASCUAL, Antoni. Bases para la delimitación del ámbito típico en el delito de corrupción privada: contribución al análisis del art. 286 bis del Código Penal según el Proyecto de Reforma de 2007. Revista de Derecho Penal y Criminología, Madrid, n. 19, p. 245-288, 2007.

GÓMEZ DE LA TORRE, Ignacio Berdugo; CERINA, Giorgio Dario. Algunas observaciones sobre la corrupción entre particulares en el Código Penal español. Revista Brasileira de Ciências Criminais, São Paulo, v. 20, n. 97, p. 217-282, jul./set. 2012.

; __ Sobre la corrupción entre particulares: convenios internacionales y derecho comparado. Revista Brasileira de Ciências Criminais, São Paulo, v. 89, mar. 2011.

; FABIÁN CAPARRÓS, Eduardo. Corrupción y derecho penal: nuevos perfiles, nuevas respuestas. Revista Brasileira de Ciências Criminais, São Paulo, v. 17, n. 81, p. 735, nov./dez. 2009.

GÓMEZ-JARA DIÉZ, Carlos. Corrupción en el sector privado: competencia desleal y o administración desleal. Revista Cuatrimestral de las Facultades de Derecho y Ciencias Económicas y Empresariales, n. 74, maio/ago. 2008.

GONTIJO, Conrado Almeida Corrêa. O crime de corrupção no setor privado: aspectos gerais e as propostas de sua tipificação na ordem jurídica brasileira. In: PASCHOAL, Janaína Conceição; SILVEIRA, Renado de Mello Jorge (Coords.). Livro Homenagem a Miguel Reale Júnior. Rio de Janeiro: GZ Ed., 2014.

GONZÁLEZ VIADA, Natacha. El derecho penal en la UE: búsqueda de la integración. In: GONZÁLEZ VIADA, Natacha. Derecho penal y globalización: cooperación penal internacional. Madrid: Marcial Pons, 2009.

HABIB, Sérgio. Brasil: quinhentos anos de corrupção. Porto Alegre: Sergio Antonio Fabris, 1994.

HALPERN, Jonathan; COSTA, Andrew. The U.K. Bribery Act and the globalization of corporate compliance. Disponível em: <http://www.mainjustice.com /justanticorruption/2011/06/03/the-u-k-bribery-act-and-the-globalization-of-coporatecompliance/>. Acesso em: 20 nov. 2013.

HOLANDA, Sérgio Buarque de. Raízes do Brasil. 26. ed. São Paulo: Companhia das Letras, 2006.

HORDER, Jeremy; ALLDRIDGE, Peter. Modern bribery law. Cambridge: Cambridge University Press, 2013. 
HOUAISS, Antônio Dicionário Houaiss da língua portuguesa. Rio de Janeiro: Objetiva, 2007.

HUBER, Barbara. La corruzione nel settore privato: diritto comparato ed internazionale. In: ACQUAROLI, Roberto; FOFFANI, Luigi (Eds.). La corruzione tra privati: esperienze comparatistiche e prospettive di riforma. Milano: Giuffrè, 2003.

La lucha contra la corrupción desde una perspectiva supranacional. Revista Penal, Madrid, n. 11, 2003.

HUET, Jean-Marie. Circulaire de présentation des nouvelles infractions de corruption active et passive dans le secteur privé issues de la Loi $\mathrm{n}^{\circ}$ 2005/750 du 4 juillet 2005. Bulletin Officiel du Ministère de la Justicia, Paris, v. 101, jan./mar. 2006.

HUNGRIA, Nelson. Comentários ao Código Penal. 2. ed. Rio de Janeiro: Forense, 1959, v. 9.

ITALIA. MINISTERO DELLA GIUSTIZIA. Disponível em:

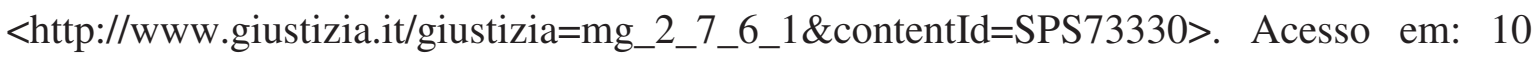
mar. 2012.

JAPIASSÚ, Carlos Eduardo Adriano. A corrupção em uma perspectiva internacional. Revista Brasileira de Ciências Criminais, São Paulo, v. 15, n. 64, p. 29-56, jan./fev. 2007.

JÍMENEZ QUERALT, Joan. Reflexiones marginales sobre la corrupción. Revista Crítica Penal y Poder, Barcelona, n. 2, mar. 2012.

JUSTICE. Criminal Procedure Rules. Disponível em: $<$ http://www.justice.gov.uk/courts/procedure-rules/criminal/rulesmenu>. Acesso em: 20 nov. 2013.

KINDHÄUSER, Urs. Presupuestos de la corrupción punible en el Estado, la economía y la sociedad. Los delitos de corrupción en el Código Penal alemán. Política Criminal: revista electrónica semestral de políticas públicas en materias penales, n. 3, 2007. Disponível em: $<$ http://www.politicacriminal.cl/n_03/a_1_3.pdf $>$.

LAW COMMISSION REFORMING THE LAW. Legislating the Criminal Code: Corruption (1998) $\quad$ n. 248.2 Disponível em: $<$ http://lawcommission.justice.gov.uk/docs/lc248_Legislating_the_Criminal_Code_Corrup tion.pdf>.

Reforming bribery: a Consultation Paper n. 145, 2008. Disponível em: <http://www.lawcom.gov.uk/bribery.htm>. Acesso em: 20 nov. 2013. 
LEVIANU, Roberto. Controle penal da corrupção. 2004. Tese (Doutorado) - Faculdade de Direito, Universidade de São Paulo, São Paulo, 2004.

LOZANO GARCÍA, María Belén. Las debilidades del gobierno corporativo en los casos de corrupción: el papel del Consejo de Administración. In: RODRÍGUEZ GARCÍA, Nicolás; FABIÁN CAPARRÓS, Eduardo (Coords.). La Corrupción en un mundo globalizado. Salamanca: Ratio Legis, 2000.

LUCAS DE LEYSSAC, Marie Paule. Il delitto di corruzione dei dipendenti in Francia. In: ACQUAROLI, Roberto; FOFFANI, Luigi (Eds.). La corruzione tra privati: esperienze comparatistiche e prospettive di riforma. Milano: Giuffrè, 2003.

MARQUES, José Frederico. Elementos de direito processual penal. 3. atual. Campinas: Millennium, 2009. v. 1.

MATELLANES RODRÍGUEZ, Nuria. El delito de cohecho de funcionarios nacionales: condicionantes internacionales y principales aspectos de su nueva regulación en el Código Penal español. Revista Brasileira de Ciências Criminais, São Paulo, v. 19, n. 89, p. 355385, mar./abr. 2011.

MAXIMILIANO, Carlos. Hermenêutica e aplicação do direito. 19. ed. São Paulo: Forense, 2009.

MAZZACUVA, Nicola. Gli artt. 2634 e 2635 c.c.: Diritto penale simbolico e necessaria frammentarietà dell'intervento punitivo. In: ACQUAROLI, Roberto; FOFFANI, Luigi (Eds.). La corruzione tra privati: esperienze comparatistiche e prospettive di riforma. Milano: Giuffrè, 2003.

MEDAUAR, Odete. Direito administrativo moderno. 12. ed. atual. São Paulo: Ed. Revista dos Tribunais, 2008.

MENDES, Gilmar Ferreira; COELHO, Inocêncio Mártires; GONET BRANCO, Paulo Gustavo. Curso de direito constitucional. 3. ed. São Paulo: Saraiva, 2008.

MESTRE DELGADO, Esteban. Delitos contra el patrimonio y contra el orden socioeconómico. In: LAMARCA PÉREZ, Carmen; MESTRE DELGADO, Esteban; RODRÍGUEZ NÚÑEZ, Alicia (Org.). Delitos y faltas: la Parte Especial del Derecho Penal. Madrid: Colex, 2012.

MILITELLO, Vicenzo. Corruzione tra privati e scelte di incriminazzione: le incertezze del nuovo reato societario. In: ACQUAROLI, Roberto; FOFFANI, Luigi (Eds.). La corruzione tra privati: esperienze comparatistiche e prospettive di riforma. Milano: Giuffrè, 2003. 
MINISTRY OF JUSTICE. The Bribery Act 2010: Guidance about procedures which relevant commercial organisations can put into place to prevent persons associated with them from bribing, 2010. Disponível em: <www.justice.gov.uk/guidance/bribery.Hmt>. Acesso em: 20 nov. 2013.

MIR PUIG, Santiago. Derecho penal: parte general. 6. ed. Buenos Aires: BdeF Editorial, 2009.

Derecho penal: parte general. 8. ed. 2.reimpr. Buenos Aires: BdeF Editorial, 2009.

MUÑOZ CONDE, Francisco. Derecho penal: parte especial. 18. ed. rev. Valencia: Tirant lo Blanch, 2010.

MURIAL PATINO, María Victoria. Aproximación macroeconómica al fenómeno de la corrupción. In: RODRÍGUEZ GARCÍA, Nicolás; FABIÁN CAPARRÓS, Eduardo (Coords.). La corrupción en un mundo globalizado. Salamanca: Ratio Legis, 2000.

NAPOLEONI, Valerio. Quale modello di intervento penale per l'ordinamento italiano? In: ACQUAROLI, Roberto; FOFFANI, Luigi (Eds.). La corruzione tra privati: esperienze comparatistiche e prospettive di reforma. Milano: Giuffrè, 2003. p. 281-286.

NASCIMENTO, Amauri Mascaro. Curso de direito do trabalho. 23. ed. São Paulo: Saraiva, 2008.

NAVARRO FRÍAS, Irene; MELERO BOSCH, Lourdes. Corrupción entre particulares y tutela del mercado. Revista para el Análisis del Derecho (InDret), Barcelona, n. 4, out. 2011.

NIETO MARTÍN, Adán. La corruzione nel settore privato: riflessioni sull'ordinamento spagnolo. In: ACQUAROLI, Roberto; FOFFANI, Luigi (Eds.). La corruzione tra privati: esperienze comparatistiche e prospettive di riforma. Milano: Giuffrè, 2003.

Fundamentos constitucionales del sistema europeo de derecho penal. Direito e Cidadania, Cabo Verde, v. 7, n. 22, 2005.

OLIVEIRA, Edmundo. Crimes de corrupção. Rio de Janeiro: Forense, 1991.

ORGANIZAÇÃO DA UNIDADE AFRICANA (OUA). Conselho Económico, Social e Cultural da União. Acto Constitutivo da União Africana. Disponível em: $<$ http://www.fd.uc.pt/CI/CEE/OI/OUA/acto_constitutivo-uniao-africana.htm>.

ORTIZ, Mariana Tranchesi. Concurso de agentes nos delitos especiais. São Paulo: IBCCRIM, 2011. 
OTERO GONZÁLEZ, Pilar. Corrupción entre particulares. Eunomia: revista en cultura de la legalidad, n. 3, sep. 2012/feb. 2013.

PAGLIARO, Antonio. La lotta contro la corruzione e la recente esperienza italiana mani pulite. Rivista Trimestrale di Diritto Penale dell'Economia, Padova, v. 10, n. 4, ott./dic. 1997.

PAGOTTO, Leopoldo. Esforços globais anticorrupção e seus reflexos no Brasil. In: DEL DEBBIO, Alessandra; MAEDA, Bruno Carneiro; AYRES, Carlos Henrique (Coords.). Temas de anticorrupção e compliance. Rio de Janeiro: Elsevier, 2013.

PERDIGÃO, Carlos Frederico Marques. Manual do Código Penal brazileiro: estudos syntheticos e praticos. Rio de Janeiro: D.L. Garnier, 1882. t. 1.

PEREIRA, Caio Mário da Silva. Instituições de direito civil. 21. ed. Rio de Janeiro: Forense, 2006. v. 1.

PÉREZ CEPEDA, Ana Isabel; BENITO SANCHÉZ, Cermen Demelsa. La política criminal internacional contra la corrupción. Revista Brasileira de Ciências Criminais, São Paulo, v. 89, mar. 2011.

; METALLANES RODRÍGUEZ, Nuria. El delito de cohecho de funcionarios nacionales: condicionantes internacionales y principales aspectos de su nueva regulación en el Código Penal español. Revista Brasileira de Ciências Criminais, São Paulo, v. 89, mar. 2011.

PIMENTEL, Manoel Pedro. Direito penal econômico. São Paulo: Ed. Revista dos Tribunais, 1973.

POLAINO NAVARRETE, Miguel (Dir.). Lecciones de derecho penal: parte especial. Madrid: Tecnos, 2011.t. 2.

PORTO, Luiz Guilherme Moreira. Tipicidade nos crimes de falsidade documental em face do bem jurídico protegido. 203 f. Dissertação (Mestrado em Direito) - Faculdade de Direito, Universidade de São Paulo, São Paulo, 2002.

PRADO, Luiz Régis. Curso de direito penal brasileiro. 5. ed. São Paulo: Ed. Revista dos Tribunais, 2008. v. 3.

A Lei 10.467/2002 e os novos crimes de corrupção e tráfico de influência internacional. Revista dos Tribunais, São Paulo, v. 91, n. 803, p. 441-558, set. 2002. 
QUERALT JIMÉNEZ, Joan. Derecho penal español: parte especial. 6. ed. Barcelona: Atelier, 2010.

- Reflexiones marginales sobre la corrupción. Revista Crítica Penal y Poder, Barcelona, n. 2, mar. 2012.

RANDO CASEMEIRO, Pablo. Delitos contra el mercado y los consumidores. In: POLAINO NAVARRETE, Miguel (Dir.). Lecciones de derecho penal: parte especial. Madrid: Tecnos, 2011. t. 2.

RANGEL, Vicente Marotta. Direito e relações internacionais. 8. ed. São Paulo: Ed. Revista dos Tribunais, 2005.

REALE, Miguel. Lições preliminares de direito. 15. ed. São Paulo: Saraiva, 1987.

REALE JÚNIOR, Miguel. A corrupção no setor privado. In: SEMINÁRIO INTERNACIONAL DE DIREITO PENAL DO INSTITUTO BRASILEIRO DE CIÊNCIAS CRIMINAIS, 17. São Paulo, 2012.

Dever de lealdade do administrador da empresa no Direito Penal. In: REALE, Miguel; REALE JÚNIOR, Miguel; REALE FERRARI, Eduardo (Orgs.). Experiências do direito. Campinas: Millennium, 2004.

. Direito penal aplicado, 3. São Paulo: Ed. Revista dos Tribunais, 1994.

Instituições de direito penal: parte geral. 2. ed. Rio de Janeiro: Forense, 2006. v. 1.

Instituições de direito penal: parte geral. 4. ed. Rio de Janeiro: Forense, 2013. v. 1.

. Razão e subjetividade no direito penal. Revista da Associação Brasileira de Professores de Ciências Penais, São Paulo, v. 0, 2004.

REQUIÃO, Rubens. Curso de direito comercial. 25. ed. São Paulo: Saraiva, 2007. v. 2.

ROSAS OLIVA, Juan Ignacio. Consideraciones para la tipificación de un delito contra la corrupción en el sector privado en España. Cuadernos de Política Criminal, Madrid, n. 99, 2009.

ROSENN, Keith S. The Jeito: Brazil's institutional bypass of the formal legal system and its developmental implications. The American Journal of Comparative Law, v. 19, 1971.

ROSS, Sthepen; WESTERFIELD, Randolph; JORDAN, Bradford. Administração financeira. 8. ed. São Paulo: McGraw Hill, 2008. 
SALVADOR NETTO, Alamiro Velludo. Direito penal e propriedade privada: a racionalidade do sistema penal na tutela do patrimônio. 2013. Tese (Livre Docência) Faculdade de Direito, Universidade de São Paulo, São Paulo, 2013.

SÁNCHEZ MELGAR, Julián. La corrupción en el sector privado. Revista Xurídica Galega, Pontevedra, n. 63, 2009.

SCALLY, Greg. Defining corruption: a comparison on the substantive criminal law of public corruption in the United States and the United Kingdom. Disponível em: <http://dl.tufts.edu/catalog/tufts:UA015.012.075.00012>. Acesso em: 20 nov. 2013.

SCHROTH, Peter. The African Union Convention on Preventing and Combating Corruption. Journal of African Law, London, v. 49, n. 1, 2005.

SEMINARA, Sergio. Gli interessi tutelati nei reati di corruzione. Rivista Italiana di Diritto e Procedura Penale, Milano, v. 36, n. 3, p. 951-993, Lug./sett. 1993.

Quale modello di intervento penale per l'ordinamento italiano? In: ACQUAROLI, Roberto; FOFFANI, Luigi (Eds.). La corruzione tra privati: esperienze comparatistiche e prospettive di riforma. Milano: Giuffrè, 2003.

SERRANO GÓMEZ, Alfonso; SERRANO MAÍlLO, Alfonso. Derecho penal: parte especial. 16. ed. Madrid: Dykinson, 2010.

; ___ _ SERRANO TÁRRAGA, María Dolores; VÁSQUEZ GONZÁLEZ, Carlos (Orgs.). Curso de derecho penal: parte especial. Madrid: Dykinson, 2012.

SILVA, José Afonso da. Curso de direito constitucional positivo. 18. ed. São Paulo: Malheiros Ed., 2000.

SILVEIRA, Renato de Mello Jorge. Direito penal econômico como direito penal de perigo. São Paulo: Ed. Revista dos Tribunais, 2006.

SPENA, Alessandro. Punire la corruzione privata? Un inventario di perplessità políticocriminali. Rivista Trimestrale di Diritto Penale dell'Economia, Milano, ano 20, n. 4, ott./dic. 2007.

SULLIVAN, Bob. Reformulating bribery: a legal critique of the Bribery Act 2010. In: HORDER, Jeremy; ALLDRIDGE, Peter (Ed.). Modern bribery law. Cambridge: Cambridge University Press, 2013.

SULLIVAN, Robert. La risposta legislativa alla corruzione in Inghilterra. In: ACQUAROLI, Roberto; FOFFANI, Luigi (Eds.). La corruzione tra privati: esperienze comparatistiche e prospettive di riforma. Milano: Giuffrè, 2003. 
TAK, Peter. Il reati di corruzione privata in Olanda. In: ACQUAROLI, Roberto; FOFFANI, Luigi (Eds.). La corruzione tra privati: esperienze comparatistiche e prospettive di riforma. Milano: Giuffrè, 2003.

THE 2013 CORRUPTION perceptions index measures the perceived levels of public sector corruption in 177 countries and territories. Disponível em: <http://cpi.transparency.org/cpi2013/results/>.

TIEDEMANN, Klaus. Frode, corruzione e armonizazzione giuridica in Europa. In: Rivista di Diritto Penale dell'Economia, Padova, v. 20, n. 1/2, gen./giug. 2007.

Introducción. In: ARROYO ZAPATERO, Luis; NIETO MARTÍN, Adán (Coords.). Fraude y corrupción en el derecho penal económico europeo: eurodelitos de corrupción y fraude. Cuenca: Ediciones de la Universidad Castilla-la Mancha, 2006.

Manual de derecho penal económico: parte general y especial. Valencia: Tirant lo Blanch, 2010.

. Protección penal de la competencia. In: TIEDEMANN, Klaus; NIETO MARTÍN, Adán (Orgs.). Eurodelitos: el derecho penal económico en la Unión Europea. Cuenca: UCLM, 2004.

TOURINHO FILHO, Fernando da Costa. Processo penal. 30. ed. São Paulo: Saraiva, 2008. v. 1.

TRANSPARENCY INTERNATIONAL. Corruption Perceptions Index 2012. Disponível em: <http://www.transparency.org/cpi2012/results>. Acesso em: 07 jan. 2014.

Corruption Perceptions Index 2013. Disponível em:

<http://www.transparency.org/cpi2013/results>. Acesso em: 07 jan. 2014.

UDOMBANA, Nsongurua J. Fighting corruption seriously? Africa's Anti-corruption Convention. Singapore Journal of International \& Comparative Law, Singapura, v. 7, 2003.

UNIÃO EUROPÉIA. Conselho da União Européia. Decisão-Quadro 2003/568/JAI do Conselho de 22 de Julho de 2003 relativa ao combate à corrupção no sector privado. Jornal Oficial da União Europeia, p. 54-56, 31 jul. 2003. Disponível em: $<$ http://www.dgpj.mj.pt/sections/relacoes-internacionais/anexos/2003-568-jaidecisao/downloadFile/file/DQ_2003.568.JAI_Corrupcao_no_sector_privado.pdf?nocache =1199980661.99>L>. Acesso em: 30 jun. 2014 . 
UNITED NATIONS. International Anti-Corruption Day. 9 Dec. Disponível em: $<$ http://www.un.org/en/events/anticorruptionday/>.

. Report of the Ad Hoc Committee for the Negotiation of a Convention Against Corruption on its third session, held in Vienna, from 30 September to 11 October 2002. A/AC.261/9. Disponível em: $<$ https://www.unodc.org/pdf/crime/convention_corruption/session_4/9e.pdf>.

UNITED NATIONS DEVELOPMENT PROGRAMME. Disponível em: $<$ http://hdr.undp.org/en/media/HDR_2011_PT_Complete.pdf $>$.

VENOSA, Sílvio de Salvo. Direito civil: parte geral. 6. ed. São Paulo: Atlas, 2006.

VENTURA PÜSCHEL, Arturo. Corrupción entre particulares. In: CABEZA OLMEDA, Araceli Manjón; VENTURA PÜSCHEL, Arturo (Orgs.). Derecho penal español: parte especial (II). Valencia: Tirant lo Blanch, 2011.

VERÇOSA, Haroldo Malheiros Duclerc. Curso de direito comercial. São Paulo: Malheiros Ed., 2006. v. 2.

VÉRON, Michel. Droit pénal spécial. 14. ed. Paris: Sirey, 2012.

VIVES ANTÓN, Tomás; ORTS BERENGUER, Enrique; CARBONELL MATEU, Juan Carlos; GONZÁleZ CUSSAC, José Luis; BUJÁN PÉREZ, Carlos Martínez. Derecho penal: parte especial. 3. ed. Valencia: Tirant lo Blanch, 2010.

VOGEL, Joachim. La tutela penale contro la corruzione nel settore privato: l'esperienza Tedesca. In: ACQUAROLI, Roberto; FOFFANI, Luigi (Eds.). La corruzione tra privati: esperienze comparatistiche e prospettive di riforma. Milano: Giuffrè, 2003.

WEBB, Philippa. The United Nations Convention Against Corruption: global achievement or missed opportunity? Journal of International Economic Law, Oxford, v. 8, n. 1, p. 191$229,2005$.

WOUTERS, Jan; RYNGAERT, Cedric; CLOOTS, Ann Sofie. The fight against corruption in international law. Leuven Centre for Global Governance Studies Working Paper n. 94, Bélgica, July 2012.

WUNDERLICH, Alexandre. Dos Crimes Contra a Administração Pública. In: REALE JÚNIOR, Miguel (Coord.). Direito penal: jurisprudência em debate. Rio de Janeiro: GZ Ed., 2013. v. 4.

ZANNOTTI, Roberto. La corruzione privata: una previsione utile nel nostro ordinamento: riflessioni su un dibattito in corso. L'Indice Penale, Padova, v. 8, n. 2, mag./ago. 2005. 